\title{
Impact of Personal Experiences and Emotionality on Passing the Childhood Vaccination Programme
}

\author{
Lucia Ludvigh Cintulova \\ St. Elisabeth University of Health and Social Work \\ Pavol Beňo \\ University in Trnava \\ Ingrid Juhasova \\ University of Polytechnics Jihlava
}

Anti-vaccination campaigns have spread a negative impact on the willingness of parents to get their children vaccinated that's why we focused on the factors that influence whether the children pass vaccination programme valid in Slovakia. The emotionality may have a great impact on the decision making of mother about childhood vaccination including awareness of life-threatening diseases and purpose of the vaccine in the general. The research has shown that less than $30 \%$ of sample involves parents who have refused to vaccinate. This is in spite of the fact that life-threatening diseases have been greatly reduced due to mandatory vaccination programs through the years in Slovakia. The data analysed the attitudes of 875 mothers who have two-year old children. We wanted to know the affects, of their emotional beliefs on decision-making about getting their children vaccinated.

\section{INTRODUCTION}

The parents complain that the quality of information that is provided by the national health authorities about the benefits and risks of vaccination is not very well done. It is not persuasive that the benefits are worth it. Instead they decide that not to vaccinate is the better option. Their decisions are based upon some stories. They decide without the full resource of verified facts about the benefits.

We wanted to understand the inconsistencies and differences of opinions between the professionals and parents as well. We wanted to understand the feelings about ethical dilemmas that they face. Thus, we can learn their confusion, fear and mistrust in the compulsory vaccination system. It is more difficult to look for the solutions when the general population of parents are making their decisions based upon their emotions.

\section{Emotionality and Vaccination}

It is increasingly possible to research health related information on the internet. Research has shown that information provided through stories and narratives influences how people decide what kind of 
treatment they will get. The stories that they read about on the internet influences their decisions often times more than the statistics and facts that are provided by the medical authorities. There is an inverse relation between the number of narratives reporting something bad after the vaccinations and the parents' decision to vaccination. These stories increase the perceived risks of vaccinating. The study emphasizes that there is a stronger influence of the number of narratives versus the actual statistical information that shows benefits versus risks. The results are that the highly emotional narratives had a greater impact on the perceptions of vaccination (Betsch, Ulshöfer, Renkewitz, and Betsch, 2011)

There is a differential impact of the message connected to vaccination aspects that influence the degree of perceived risk associated with childhood vaccination. Research has shown if the people start to believe the broad spectrum of information and stories from internet that vaccination can or will cause the possible bad consequences of avaccination; they are less willing to go through the vaccination program.. The decision making is not made on rational thinking but on emotions. The fear of a bad outcome affects how a person chooses what to do in a given situation

(Ferguson, Bibby, and Leaviss, 2003). Based on this evidence, due to the recent controversies regarding vaccine side-effects, MMR immunization is being perceived as a 'solution' that also produces other health problems (Bellaby, P., 2003). Rothman and Salovey (Rothman, Salovey, Antone, Keough, and Martin, 1993) have also shown that the value that people place in the treatments are very important when people respond to it according to their feelings.

Another study looks at the interaction between the content of the treatment and how it is formatted on the how the audience receives the message. Audiences using a peripheral route (pictures of someone after a vaccination) to persuasion are more likely to agree with the message. When the source is, in their opinion, reliable and honest and the message has high quality production features, it carries a lot of weight even if the argument itself is weak. This shows that strong arguments presented in the public service announcement will appeal to emotions (Kang, Cappella, and Fishbein, 2006).

The de Martino study (De Martino, Kumaran, Seymour, and Dolan, 2006) highlights the importance of including emotional processes and suggests how the brain may modify the effect of these biasing influences to fit with their own rationality. This so-called "framing effect" that was specifically associated with amygdala activity, suggesting a key role for an emotional system in mediating decision biases. Human being involves the range of additional emotional information into the process of decisionmaking (De Martino, Kumaran, Seymour, and Dolan, 2006).

TABLE 1

FRAMING EFFECT MODEL

\begin{tabular}{|l|ll|}
\multicolumn{1}{l|}{ Frame } & Model A & Model B \\
\hline Positive & Vaccine saved about 1,5 million & $44 \%$ - saved lives \\
& women per year & $56 \%$ - no women were saved \\
Negative & 2 million women died & $44 \%$ - nobody died \\
& & $55 \%$ - of all women died \\
\hline
\end{tabular}

They called it the framing effect, a key aspect of prospect theory. The framing effect is the model that looks at the influence of emotions on how one makes a decision. For example, we describe the framing effect in regards on the vaccination for cervical cancer. In case of a positive and negative frame, model A and model B are identical, only presented in a different way.

Abhyankar presents the impact of framing on the willingness to vaccinate a child (Abhyankar, O'connor, and Lawton, 2008). He prefers the advantages of the negative frame effect to the positive one. The results from the research claim that the more effective approach than describing the safety of vaccines may be to highlight risks from the disease. Messages describing potential dangers put individuals into the "domain of losses," which makes them more tolerant of perceived risks than messages about the benefits of vaccines. 
Acceptance of vaccination increased when parents received information about the negative model if they did not vaccinate. Some considerations for why people choose to vaccinate included the beliefs and attitudes that one holds. These are the perceived risk of HPV infection, the perceived safety and effectiveness of HPV vaccines, the perceived encouragement from their physician to vaccinate, and their previous health behaviour, for example, HIV testing (Gerend, Shepherd, 2007).

One's motivation and ability to process the message are key predictors of one focus of attention. Some characteristics of how the message is presented may catch people's attention without their awareness. For example, attention to the message is not forced when the message shows pictures of damages caused by vaccination. This creates a negative perception that vaccination is dangerous (Frey, Eagly, 1993).

None of the pro-vaccine messages created by public health authorities increased anyone's intentions to vaccinate with MMR. They targeted a nationally representative sample of parents who have children age 17 years or younger. Information to correct misperceptions about the vaccine/autism nonetheless decreased intentions to vaccinate among parents who had the least favourable attitudes toward vaccines. Images of children who have MMR and a story about a child who had measles actually increased beliefs in serious vaccine side effects (Nyhan, Reifler, Richey, and Freed, 2014). The study emphasises the strong emotional impact of public information about vaccine on the parental decision-making about vaccination for toddlers (Nyhan, Reifler, Richey, and Freed, 2014; Marsh, Malik, Shapiro, Omer, and Frew, 2013).

Our study was inspired by research of Nyhan (Nyhan, Reifler, Richey, and Freed, 2014) which focused on analysing the effect of 4 different types of information about vaccination and how it influenced decision making of parents to vaccinate their children. This was with a research group of 1759 parents. The results showed the high impact of emotions when presenting information toward the desire to get a child vaccinated. Our study is aimed at analysing the impact of emotionality on the parental decisions to reject vaccination. It includes a questionnaire with different levels of emotional perceptions.

\section{METHODOLOGY}

The study was designed as the quantitative research based on the standardized questionnaire adopted from the Slovak public health institution (RÚVZ SR). It was modified to analyse attitudes of mothers toward childhood vaccination. The sample was 875 mothers of toddlers. A three-part survey was used to collect data from January to May 2018 including the sample criteria a) the age of mother from 20 until 40 years, b) the age of children - mothers of toddlers, c) the counselling visits at the pediatrician - minimum once per three months; d) taking care of a child for at least 18 months. e) agreement with participation in the research study; f) the marriage. 875 mothers were recruited and data were collected by 1 . direct contact at pediatrician ambulances, at ambulances of medical specialists visiting by toddlers and at Mother Care Centres and 2. using online tools and social network - Forum for health, Blue Horse, Facebook, Montessori Group.

The research study is based on the 3 domains analysing the impact of the various factors and emotionality on the decision-making about the compulsory and optional vaccination of toddlers.

\section{Demographic Factors Influencing the Attitudes to Vaccination}

We came out of a reflection of the impact of demographic indicators on the willingness of parents to get children vaccinated that have shown other research e.g (Smith, Chu, and Barker, 2004) - there should be positive correlation between willingness to get a child vaccinated and education; on the other hand - age, number of children (maternity) and marriage should have a negative correlation with the attitude to childhood vaccination .

\section{Attitudes of Mothers to Vaccination and Subjective Perceptions of Vaccine Risks}

There are many factors influencing the decision making of mothers to get a child vaccinated. e.g. Nyhan (Nyhan, Reifler, Richey, and Freed, 2014). 


\section{Effect of Emotionality on Attitudes to Vaccination and Decision Making}

It is based on the research in the basis on high emotional narratives had a greater impact on the perceptions of vaccine risks (Betsch, Ulshöfer, Renkewitz, and Betsch, 2011) and di Martino study that human being potentially broad range of additional emotional information into the decision process (De Martino, Kumaran, Seymour, and Dolan, 2006).

Hypothesis 1: There is the significant relation between demographic variables and the attitudes to childhood vaccinatiom identified by the study.

Hypothesis 2: There are various attitudes to vaccination in the relation to the refusal of childhood vaccination.

Hypothesis 3: There is the significant relation between the emotionality that influences decision-making about vaccination.

Coding and statistical analyses of data were done by using the SPSS 7.0 package program. Percentage was used to evaluate the parameters of age, marital status, educational, occupational status, the district of living and maternity. The $t$ test was applied to determine differences between the mean attitude to vaccination and emotionality scores according to maternity and the education. Pearson correlation analysis was used to detect the relation between attitudes to vaccination, emotional domains and decision making. Significance in all statistical analyses was defined as $p<0.05$.

\section{RESULTS}

The research is based on the analysing the attitudes of mothers to vaccination programme including vaccine Infanrix hexa and synflorix/prevenar13 + MMR vaccine and exploring relation between emotionality and decision-making about childhood vaccination.

Using Multivariate Analysis of Variance, which was designed to compare the levels of qualitative variables in several groups in which the base set is decomposed into multiple nominal-type variables, we have identified the following:

\section{Completed Education}

( $56.3 \%$ with university degree: $43.7 \%$ of secondary education) has no impact on attitude to childhood vaccination. Limits: Achieved education does not have to reflect correctly the educational level, in view of the possible high number of mothers who do not have health education or medical degree, they have lay information about vaccination.

\section{Parenting}

For the purposes of this research, all respondents, whether they had already take care of children at the time of enrolment, are referred to as "mothers of toddlers". Only mothers with one and more children were included in the research. A positive correlation between mothers' willingness to vaccinate children and the number of children in the family has been identified. Mothers with at least two children have a positive attitude towards vaccinations compared to mothers who are firstborn with a significantly lower willingness to vaccinate. Significant influence of parenthood on decision-making on vaccination has been shown $(\mathrm{p}=0.0435)$ : Mothers with one child are less willing to vaccinate children compared to other mothers. Limits. The fathers were not included in the research study due to the most part of care is on the shoulders of mothers including visits at paediatrician ambulances, at mother care centres and also social networks such as Blue Horse, Montessori Group are mostly browsed by women. That's why we did not get in touch with fathers during study recruitment.

There is also a significant relationship between the age and the mother's attitudes to childhood vaccination $(\mathrm{p}=0.0372)$. Younger mothers up to 35 years-old are more willing to risk, they have a higher 
negative attitude to vaccination, and children are less or not vaccinated compared to older mothers over 35 who are less willing to risk and face the risks of non-vaccination. Younger mothers prefer healthy lifestyles, building immunity through a natural infectious pathway before artificial resistance by vaccinations, older women prefer to build collective immunity by nationwide vaccination $(\mathrm{p}=0.0341)$.

\section{Place of Residence and Region}

The place of residence doesn't influence the variable of attitudes to vaccination $(p=0.257)$. If the mothers lives in the village or in the city it has not showed significant differences in attitudes towards vaccination, the region where they came from $(\mathrm{p}=0.0274)$, the mothers from Bratislava $(24 \%)$ and Banská Bystrica (21\%) have the highest negative attitudes towards vaccinations compared to others, the most positive attitudes were expressed by mothers living in Prešov region (28\%) and Košice region $(25 \%)$. Limits. The sample was more-less evenly divided into 8 Slovak regions. The typical phenomenon is that the most of Slovak inhabitants leave from the east regions to Bratislava district that can influence the outcomes of the research.

\section{Social Status}

The study has not showed a correlation between job-placement and attitude to vaccination. A strong sample consisted of women on parental leave and women working part-time $(p=0.269)$. Limits. We did not focus on the specific professions of the sample due the most of them were on maternity or parental leave. It would be interesting to consider this variable as well.

TABLE 2

\section{DEMOGRAPHIC FACTORS OF THE SAMPLE}

\begin{tabular}{|c|c|c|c|c|c|}
\hline $\begin{array}{l}\text { Variables/ } \\
\text { demographic } \\
\text { characteristics }\end{array}$ & $\begin{array}{l}\text { Ambulances } \\
\text { and mother } \\
n=386\end{array}$ & $\begin{array}{l}\text { for mothers } \\
\text { care centres }\end{array}$ & $\begin{array}{l}\text { Online } \\
\text { Recruitment }\end{array}$ & $\begin{array}{l}\text { Social } \\
\text { network } \\
n=489\end{array}$ & \\
\hline & $\mathrm{N}(\%)$ & Mean & $\mathrm{N}(\%)$ & Mean & $\mathrm{p}$ \\
\hline Education & & 1.0 & & 2.0 & $<.231$ \\
\hline University & $229(59.32)$ & & $207(42.33)$ & & \\
\hline High School & $157(40.67)$ & & $282(57.66)$ & & \\
\hline Age & & 29.4 & & 31.3 & $<.034$ \\
\hline 22-24 years & $91(23.57)$ & & $92(18.81)$ & & \\
\hline $25-29$ years & $152(39.37)$ & & 133 (27.19) & & $<.026$ \\
\hline $30-34$ years & $76(19.69)$ & & $157(32.10)$ & & \\
\hline Over 35 years & $67(17.35)$ & & $107(21.88)$ & & \\
\hline Residence & & 2.0 & & 2.0 & $<.164$ \\
\hline Village & $155(40.15)$ & & $93(19.01)$ & & \\
\hline City & $231(59.85)$ & & $296(60.53)$ & & \\
\hline Marriage & & 1.0 & & 2.0 & $<.073$ \\
\hline Get Married & $204(52.84)$ & & $198(38.65)$ & & \\
\hline $\begin{array}{l}\text { Engaged } \\
\text { (common } \\
\text { household) }\end{array}$ & $161(41.70)$ & & $279(57.05)$ & & $<.048$ \\
\hline Divorced & $21(5.44)$ & & $12(2.45)$ & & \\
\hline Parenting & & & & & $<.065$ \\
\hline One child & $151(39.11)$ & & $254(51.94)$ & & $<.041$ \\
\hline 2 children & $235(60.88)$ & & $217(44.37)$ & & $<.037$ \\
\hline More than 2 & $23(4.70)$ & & $18(3.68)$ & & \\
\hline
\end{tabular}




\begin{tabular}{|c|c|c|c|c|c|}
\hline Social status & & & & & $<.235$ \\
\hline Maternity leave & $106(27.46)$ & 2.0 & $111(22.70)$ & 2.0 & \\
\hline Parental leave & $167(43.26)$ & & $203(41.51)$ & & \\
\hline Part-time job & $82(21.24)$ & & $136(27.81)$ & & \\
\hline Unemployed & $31(8.03)$ & & $39(7.98)$ & & \\
\hline $\begin{array}{l}\text { Awareness of } \\
\text { vaccination }\end{array}$ & & 2.0 & & 1.0 & $<.044$ \\
\hline Good & $102(26.42)$ & & $222(45.39)$ & & \\
\hline Low & $181(46.89)$ & & $162(33.12)$ & & \\
\hline Poor & $103(26.68)$ & & $105(21.47)$ & & \\
\hline
\end{tabular}

H1: There is the significant relation between demographic variables and the attitudes to childhood vaccinatiom identified by the study.

The results figured out the correlation between attitudes to vaccination and demographic variables such as age $(\mathrm{p}=0.034)$, parenting $(\mathrm{p}=0.037)$, social status $(\mathrm{p}=0.235)$, vaccination awareness $(\mathrm{p}=0.044)$ and marriage $(\mathrm{p}=0.048)$.

Our findings suggest a necessity of increasing of vaccination awareness to eliminate false myths about vaccines and to reduce anti-vaccination campaigns breaking system of vaccination immunization. Study of Betsch and Wicker (Betsch, Wicker, 2012) showed that healthcare professionals suffer from a lack of awareness about national guidelines and a lack of knowledge about vaccines (both specific attributes including beliefs about contraindications, as well as beliefs about vaccine-related health damages).It practicaly lead to decreasing number of vaccinated children and increasing parental refusals of childhood vaccination.

\section{The Attitudes of Mothers to Vaccination of Toddlers}

\section{H2: There are various attitudes to vaccination in the relation to the refusal of childhood vaccination.}

The results show three attitudes to childhood vaccination based on final decision-making to get a toddler vaccinated. Our findings identified 3 types of attitudes: 1. positive attitude to vaccination including passing compulsory vaccination programme for toddlers valid in Slovakia and agreeing with importance of collective immunity; 2. negative attitude to vaccination characterized by parental refusal of vaccination and highlighting vaccine risks, vaccine side effects and natural immunity process. 3 . Neutral attitude presenting the willingness to re-vaccinate a child in the future and dual approach to vaccine risks.

Research findings suggest the positive pro-vaccine information are not efficacy and pro-vaccine intervention does not increase intent to vaccinate among mothers of toddlers who are the least favourable toward vaccines and the effectiveness of those messages may vary depending on parental attitudes toward vaccines. There is a correlation in emotional perception about information about risks and vaccination side effects and the mothers' decision-making about vaccination.

Exploratory factor analysis using the 20 items measuring beliefs and attitudes identified 8 factors, or subscales, that were used in subsequent analyses. These factors included normative beliefs, or emotional beliefs influencing the decision-making (two items, $\mathrm{p}=0.129$ ), barriers to vaccination related to vaccination side effects and risks (three items, $\mathrm{p}=0.032$ ), practical barriers related to vaccination (two items, $\mathrm{p}=0.076$ ), barriers related to insufficient knowledge about childhood vaccination (two items, $p=0.079$ ), benefits of vaccination related to health and safety (two items, $p=0.042$ ), benefits of vaccination related to protection of population (two items, $\mathrm{p}=0.034$ ), prevention of related disease (one item, $\mathrm{p}=0.025$ ), fear of shots in general (two items, $\mathrm{p}=0.179$ ). We also included a scale assessing MMR-related stigma, which we developed previously ( 8 items, $\mathrm{p}=0.78$ ). Cronbach's alpha for the two-item scale measuring future attitudes to vaccination and willingness of re-vaccination was $p=0.026$ and believe in the change of vaccination programme to optional $(p=0.014)$. 
TABLE 3

MOTHERS ATTITUDES TO TODDLE'S VACCINATION

\begin{tabular}{|l|l|l|}
\hline $\begin{array}{l}\text { Decision-making } \\
\text { Statement }\end{array}$ & $\begin{array}{l}1 \text { Strongly } \\
\text { agree }\end{array}$ & $\begin{array}{l}4 \text { Totally } \\
\text { disagree }\end{array}$ \\
\hline Vaccination is dangerous & 0.0325 & -0.214 \\
\hline Vaccination is a high business & 0.1294 & 0.0874 \\
\hline Vaccination doesn't have a real sense & 0.0753 & -0.0358 \\
\hline Encourage collective immunity & 0.0346 & 0.0023 \\
\hline Prevention against serious diseases & 0.0257 & 0.2562 \\
\hline Vaccination saves lives & 0.0421 & 0.3487 \\
\hline No re-vaccination in the future & 0.0267 & 0.2496 \\
\hline $\begin{array}{l}\text { Obligatory vaccination should be changed to } \\
\text { optional }\end{array}$ & 0.014 & 0.2148 \\
\hline
\end{tabular}

There are many factors influencing the decision making of mothers to vaccinate, as showed by research results in the basis of completed age. Our research findings provide a model of the most often beliefs and factors underlying mother decision about toddlers vaccination, less willingness to vaccinate a child is linked with general side effects/safety concerns (relationship observed in $24 \% \mathrm{p}=0.0226$ ), lack of perceptions of vaccine effectiveness and importance $(17 \% ; \mathrm{p}=0.0583)$, belief that vaccine causes autism $(7 \%, \mathrm{p}=0.1151)$, own and others' experiences of vaccines $(26 \%, \mathrm{p}=0.0257)$ and vaccine adverse events $(22 \%, \mathrm{p}=0.0341)$, belief anti-vaccination campaigns with the emotional basis and arguments $(23 \%, \mathrm{p}=$ $0.0325)$, belief in a danger of immune overload (8\%, $\mathrm{p}>.05)$, thinking about vaccine as a business $(5 \%, \mathrm{p}$ $=0.148)$ and belief that children receive too many shots $(3 \% \mathrm{p}=0.2174)$.

The strong findings is the correlation between attitudes to vaccination and emotionality, respectively the level of emotional power of the vaccination information appeared $(\mathrm{p}=0.0325)$.

The emotionality has been monitored on 4 levels: 1 . easily influenced by the opinions of others (family, friends, co-workers) - the presented story raises my strong emotions; 2. Influenced only by expert arguments - the presented expert arguments can convince me of the harmfulness of vaccination; 3 . Under effects of life experiences; 4. I stand for my conviction.

The study figured out relation between level of emotionality identified by the sample on the scale from 1 to 4 and attitudes to children vaccination (table4)

Many mothers are not entirely polarised in their opinions of vaccination - feeling strongly about refusal of vaccination, usually it is the mixed views and beliefs of vaccination. They hold a mixed profile of attitudes to vaccination and combine the multifactorial aspects of the decision making in the relation to the emotionality. There is a high relation with neutral attitude and decision-making about vaccination $(\mathrm{p}=0.0382)$

On the other hand, our findings have shown that a strong emotional sides affects the decision itself on vaccination mainly in the first phase of decision-making, but ultimately does not play a key role, it is a rationality under the influence of emotions, mothers are more compelled to look for more detailed information about vaccination and relevant facts that rebut in their claims of beliefs or their attitude. There is an example how emotionality and a high statement (without research evidence) can negatively influence the attitudes to vaccination. "Increased cases of autism observed over the past two decades is a result of the combined MMR vaccine, which overwhelms the immune system with three simultaneous viral infections causing increased gut permeability to neurotoxins, thereby causing irreversible brain damage leading to autism" (Wakefield, Murch, Anthony, Linnell, Casson, et al., 1998). This statement is strong enough to encourage parental refusal of MMR vaccines or even start misunderstandings and doubts about vaccination in a general. 
Table 4 presents the levels of emotionality influencing the decision-making about childhood vaccination that can be multifactorial and can based on power of spread information, temperament of the mothers and value system, associated with amygdala activity and emotional system.

\section{TABLE 4
EFFECT OF EMOTIONALITY ON ATTITUDES TO VACCINATION}

\begin{tabular}{|l|l|l|l|l|}
\hline Negative frame / level of emotionality & $\mathbf{1}$ & $\mathbf{2}$ & $\mathbf{3}$ & $\mathbf{4}$ \\
\hline $\begin{array}{l}\text { Real stories about the relation between vaccination and } \\
\text { harmful effects eg. autism }\end{array}$ & 0.044 & 0.041 & 0.158 & 0.087 \\
\hline $\begin{array}{l}\text { The amount of undesirable effects of vaccines and } \\
\text { possible negative consequences after vaccination }\end{array}$ & 0.021 & 0.028 & 0.137 & 0.049 \\
\hline $\begin{array}{l}\text { Negative personal experiences are stronger than the } \\
\text { willingness to toddlers vaccination }\end{array}$ & 0.159 & 0.033 & 0.027 & 0.172 \\
\hline $\begin{array}{l}\text { Scared stories of children with permanent consequences } \\
\text { after vaccination }\end{array}$ & 0.011 & 0.162 & 0.138 & 0.015 \\
\hline I always do according to my conviction & 0.164 & 0.154 & 0.032 & 0.005 \\
\hline Positive frame / level of emotionality non- & $\mathbf{1}$ & $\mathbf{2}$ & $\mathbf{3}$ & $\mathbf{4}$ \\
\hline False myth about vaccinations and autism & 0.129 & 0.114 & 0.036 & 0.012 \\
\hline $\begin{array}{l}\text { Dangerous risks and outcomes in case of } \\
\text { vaccination }\end{array}$ & 0.069 & 0.038 & 0.034 \\
\hline $\begin{array}{l}\text { Symptoms of infected children diseases showed in } \\
\text { media }\end{array}$ & 0.025 & 0.072 & 0.063 & 0.026 \\
\hline Scared stories infected children & 0.157 & 0.048 & 0.578 & 0.162 \\
\hline I always do according to my conviction & 0.186 & 0.050 & 0.814 & 0.135 \\
\hline Neutral frame / level of emotionality & $\mathbf{1}$ & $\mathbf{2}$ & $\mathbf{3}$ & $\mathbf{4}$ \\
\hline Vaccination should be on free choice of everyone & 0.148 & 0.136 & 0.043 & 0.076 \\
\hline Vaccination has a positive and negative aspects & 0.008 & 0.034 & 0.084 & 0.095 \\
\hline Vaccination is not for everybody & 0.143 & 0.038 & 0.027 & 0.165 \\
\hline
\end{tabular}

The study figured out relation between level of emotionality identified by the sample and attitudes to vaccination (table $4, \mathrm{p}=0.014$ ). Those who are easily influenced, they prefer negative frame to others, and they are more likely to see vaccination side effects rather than positive aspects (e.g. children with permanent damage after MMR vaccine, $\mathrm{p}=0.011$ ). People with positive frame and with strong own convictions are less likely to refuse the vaccination due to symptoms of diseases $(p=0.026)$ and nonvaccination risks $(\mathrm{p}=0.034)$. People facing personal experience with vaccination totally agreed with statement: Negative personal experiences are stronger than the willingness to toddlers' vaccination $(\mathrm{p}=0.027)$.

This fear and the belief that vaccines themselves may cause those diseases against which they are made or at least cause serious complications, make a space to the development and duration of antivaccination movements based on the negative emotions, fear and lack of trust. The mothers speak about violations of their human rights by making Slovak vaccination programme obligatory, they call for a change and freedom in choice $(31.5 \%)$. There are also neutral attitudes presenting mothers opinions: Vaccination is not for everybody (11.4\%) and vaccination brings positive and negative aspects in itself (17.6\%). 39.5\% of the sample think the vaccination programme should stay compulsory to prevent and reduce diseases, to save lives and to built collective immunity. If vaccinations decision is on free will, many Slovaks would definitely not vaccinate, which could lead to an infectious disaster, agreed by $40 \%$ of mothers. 
H3: There is the significant relation between the emotionality that influences decision-making about vaccination $(p=0,035)$.

Those who can be easily persuaded they are more likely to adapt anti-vaccination philosophy and totally refuse the childhood vaccination, they do not have medical education and they are easily influenced by the internet mistrust information about vaccination, the prefer emotionality to rationality in decision-making. They more believe about dangerous of vaccination, vaccination side effects, risks and strong vaccine shots and they prefer natural immunization to vaccination.

Information specifically covering vaccine efficacy trials, vaccination coverage, and institutional vaccine policy doesn't have impact on the positive decision-making about vaccination, on the other hand vaccine-critical websites resonate more and anti-vaccination strategies go quickly across social networks, the message frame effects strongly influence the emotionality and decision-making process that can lead to parental refusal of vaccination.

\section{DISCUSSION}

The study evaluated the association between mothers' beliefs and vaccines attitudes, the association between emotionality and their decision to delay or refuse vaccines for their toddlers, and finally the most of them do not coverage immunization program of two-years old children.

This study explored what factors are important in refusal of childhood vaccination by mothers of toddlers. Similar to Sporton study (Sporton, Francis, 2001), our research has found that most refusal of vaccination is based on deliberate decision-making of parents. Our results show that this decision is based on multiple factors, such as the lifestyle of parents, perceptions about the body and the immune system of the child, risk perception of diseases and vaccination side effects, perceived vaccine effectiveness, perceived advantages of experiencing the disease, personal negative experience with vaccination, and parents' social environment. In addition, this study shows that the use of online focus groups is an effective qualitative research method resulting in meaningful data.

Refusal of childhood vaccination may be influenced by concerns about vaccine components, low perceived likelihood and severity of the infectious diseases, and a trusting relationship with a natural healer or another respected person who doubts vaccination safety and effectiveness [16]. Hilton et al. [17] showed that some parents fear an overload of the immune system caused by combination vaccines. Additionally, the perception that vaccination is more risky than non-immunization (Smailbegovic, Laing, Bedford, 2003) and issues of harm, distrust and access might play a role in refusing childhood vaccination (Mills, Jadad, Ross, Wilson, 2005). Our findings support a important role of negative frame effects on the attitudes to childhood vaccination, the mothers with stronger emotionality about vaccination issues are less likely to get a toddler vaccinated and they prefer not to pass the vaccination programme that is compulsory in Slovakia $(\mathrm{p}=0,018)$.

According to Sporton et al. (Sporton, Francis, 2001), parents who refused vaccination made a wellconsidered decision based on an assessment of the benefits and the risks of vaccination, the child's susceptibility to the potential disease, and the acceptance of responsibility for that decision. Our research confirmed correlation between decision making and assessment of benefits and risk of vaccinations for toddlers $(\mathrm{p}=0,027)$

We have found that emotionality has an impact on decision-making about vaccination, and this effect, or the very presence of this influence, depends on the type of information message on which emotional manipulation is performed. To get deeper into the nature of this impact and more explicit interpretation, further study of this would be appropriate.

Besides the perceived risk of disease versus vaccination, our findings as well as those of Hilton et al. suggest that parents fear the immune system in infancy is not adequately developed for a good response to vaccination (Gerend, Shepherd, 2007). They apparently have not received enough information about the influence of vaccines on the immune system of their child, and their resulting doubts cause them to refuse vaccination. Mothers in this study indicated that when they start searching for information, it is hard to 
find reliable information and to make a choice from all the information they have found. Mothers also face a lot of ethical dilemmas linked to childhood vaccination that can lead to refusal Blume asks, "Isn't a critical stance towards vaccination a logical consequence of this ideological shift [towards encouraging individual rights]?" (Blume, 2006).

The implication for those seeking to create active demand for vaccination by articulating the common good is that they are likely to continue encountering tension from efforts to encourage individual rights. Building active demand at the community level may be even more challenging than building active demand at the individual level.

\section{Research Limitations}

There are some limitations of this study to be considered when interpreting the data. First, the intentional selection process of the participants and smaller sample size implicates that the study sample may not be representative of all mothers of toddlers and also focusing on the female attitudes to vaccination not including fathers in the study. Secondly, emotionality and its impacts can be analysing from different points of views, we could not cover all of them due to personal capacity, no financial support and time-schedule of the research.

\section{CONCLUSION}

Despite an enormous success of the vaccination program in the Slovakia and decreasing number of infected people by dangerous diseases or rate of preventable diseases that the vaccine, the thinking of importance of vaccination has changed from a tool of encouraging collective immunity to compulsory tool of state to support pharmaceutical business. There is increasing numbers of parents who refuse to vaccinate their children. Fear of potentially deadly diseases has been replaced by the fear of real and, more often, imaginary side effects of vaccination that is empowered by emotionality of parents and emotional arguments against vaccination not based on the long-term studies.

Our findings show the great impact of negative frame effect on attitudes to childhood vaccination. It is not easy to find solution of this problem; however, most important is to continue public education and increasing awareness about vaccination side effects and addressing vaccine refusal by respectfully listening to parental concerns and discussing the risks of non-vaccination. Study figured out that the highlighting the risks from non-vaccinated diseases is more effective than promoting of the safety of vaccines and its positive rates.

\section{REFERENCES}

Abhyankar, P., O'connor, D. B., \& Lawton, R. (2008). The role of message framing in promoting mmr vaccination: Evidence of a loss-frame advantage. Psychology, Health and Medicine, 13(1), 1-16.

Bellaby, P. (2003). Communication and miscommunication of risk: Understanding UK parents' attitudes to combined MMR vaccination. British Medical Journal, 327,725 - 728.

Benin, A.L., Wisler-Scher, D. J., Colson, E., Shapiro, E. U., \& Holmboe, E. S. (2006). Qualitative analysis of mothers' decision-making about vaccines for infants: the importance of trust. Pediatrics, 117(5), 115-117.

Betsch, C., Ulshöfer, C., Renkewitz, F., \& Betsch T. (2011). The influence of narrative v. statistical information on perceiving vaccination risks. Med Decis Making, 31(5), 742-53.

Betsch, C., \& Wicker, S. (2012). E-health use, vaccination knowledge and perception of own risk: drivers of vaccination uptake in medical students. Vaccine, 30(6), 1143-1148.

Blume, S. (2006). Anti-vaccination movements and their interpretations. Social Science \& Medicine, 62 , 628-642.

De Martino, B., Kumaran, D., Seymour, B., \& Dolan, R. J. (2006). Frames, biases, and rational decisionmaking in the human brain. Science, 313(5787), 684-687. 
Ferguson, E., Bibby, P., \& Leaviss, J. (2003). Effective design of workplace communications. Sudbury, HSE Books.

Frey, K., \& Eagly, A. (1993). Vividness can undermine the persuasiveness of messages. Journal of Personality and Social Psychology, 65(1), 3244.

Gerend, M. A., \& Shepherd, J. E. (2007). Using message framing to promote acceptance of the human papillomavirus vaccine. Health Psychology, 26(6), 745.

Hilton, S, Petticrew, M., \& Hunt K. (2006). Combined vaccines are like a sudden onslaught to the body's immune system: parental concerns about vaccine 'overload' and 'immunevulnerability'. Vaccine, 24, 4321-4327.

Kang, Y., Cappella, J., \& Fishbein, M. (2006). The attentional mechanism of message sensation value: Interaction between message sensation value and argument quality on message effectiveness. Communication Monographs, 73(4), 351-378.

Marsh, H. A., Malik, F., Shapiro, E., Omer, S. B., \& Frew, P. M. (2013). Message framing strategies to increase influenza immunization uptake among pregnant African American women. Maternal and child health journal, 1, 1-9.

Mills, E, Jadad, A. R, Ross, C., Wilson, K. Systematic review of qualitative studies exploring parental beliefs and attitudes toward childhood vaccination identifies common barriers to vaccination. $J$ Clin Epidemiol., 2005, 58, 1081-1088.

Nyhan, B., Reifler, J., Richey, S., and Freed, G. L. Effective messages in vaccine promotion: A randomized trial. Pediatrics, 2014, 133(4), 835-842.

Rothman, A., Salovey, P., Antone, C., Keough, K., and Martin, C. (1993). The influence of message framing on intentions to perform health behaviors. Journal of Experimental Social Psychology, $29,408-433$.

Smailbegovic, M.S., Laing, G.J., \& Bedford, H. (2003). Why do parents decide against immunization? The effect of health beliefs and health professionals. Child Care Health Dev., 29, 303-311.

Smith, P. J., Chu, S. Y., \& Barker, L. E. (2004). Children who have received no vaccines: who are they and where do they live? Pediatrics, 114(1), 187-195.

Sporton, R. K., \& Francis, S.A. (2001). Choosing not to immunize: are parents making informed decisions? Family Practice, 18, 181-188.

Wakefield, A. J., Murch, S.H., Anthony, A., Linnell, J., \& Casson, D. M., et al. (1998). Ileal-lymphoidnodular hyperplasia, nonspecific colitis, and pervasive developmental disorder in children. Lancet, 351(9103), 637-641. 